\title{
Carbon monoxide production during underventilated fires in corridors
}

\author{
SEBASTIAN UKLEJA ${ }^{1,3}$, MICHAEL DELICHATSIOS ${ }^{1}$, JIANPING ZHANG ${ }^{1}$ and MATHIEU \\ SUZANNE ${ }^{1,2}$, \\ ${ }^{1}$ University of Ulster, Shore Road, Newtownabbey, BT37 0QB, UK \\ ${ }^{2}$ Central Laboratory of Police Prefecture, 39bis rue de Dantzig, 75015, Paris, France \\ ${ }^{3}$ Centrum Techniki Okretowej S.A., Ship Design and Research Centre, Szczecinska 65, 80-392, \\ Gdansk, Poland
}

\begin{abstract}
This work presents experimental results and non-dimensional correlations of factors and conditions affecting carbon monoxide (CO) production in corridor-like enclosure fires. Thirty eight experiments were performed in a three metre long corridor-like enclosure having a cross section $0.5 \mathrm{~m} \times 0.5 \mathrm{~m}$, door-like openings in the front panel and a propane gas burner located near the closed end being flushed with the floor. Measurements of carbon monoxide concentrations were performed at locations inside the enclosure and also in the exhaust duct of a hood collecting the combustion products for direct comparison. Visual observations through the opening revealed that flames were detaching from the burner for tests with global equivalence ratios (GERs) greater than one for the burning inside the enclosure (underventilated fires). After detachment, flames were travelling towards the opening then finally stayed anchored in the vicinity of the opening and emerged outside. After flames were visible outside, the concentration of CO inside the corridor increases to much higher levels owing to the recirculation of gases inside the enclosure behind the flames. A correlation between $\mathrm{CO}$ concentration inside the enclosure and GER was found with $\mathrm{CO}$ increasing initially but then decreasing for high global equivalence ratios. An additional correlation was found between the $\mathrm{CO}$ yield and the GER in the enclosure before the flames reached and then, anchored at the opening of the enclosure. Finally, it was found that the ratio of $\mathrm{CO}$ to smoke yield, $\mathrm{y}_{\mathrm{co}} / \mathrm{y}_{\mathrm{s}}$, is not constant but increases for global equivalence ratios of the enclosure greater than one in contrast to its value being constant for over ventilated conditions.
\end{abstract}

KEYWORDS: compartment fires, smoke, toxicity

\section{INTRODUCTION}

Numerous attempts have been made to predict carbon monoxide formation within enclosure fires over the last fifty years. The earliest correlations were proposed in a Fire Research Note prepared in 1966 [1]. These early correlations were based on a ventilation criterion and a fuel load, however this study was criticised as "fire behaviours in these studies have not been adequately assessed, and the utility of these correlations for actual fires is limited" [2].

Studies that started to emerge in the early nineties resulted in a better understanding of CO formation and improved methods to predict its formation in fires in enclosures [2-10]. The concept of global equivalence ratio was proposed [11] but still the prediction of carbon monoxide production in enclosures is not well described. Moreover, there is also doubt if the data obtained from bench scale tests can be utilised for real fires [12].

The authors have been studying the production of smoke and carbon monoxide for underventilated enclosure and corridor fires for the last few years [13-16] and this paper is focused on the production of carbon monoxide inside and outside of a corridor-like enclosure. It is organised as follows: After a short review of the literature, the experimental methodology is described followed by results and discussions. Finally, conclusions are drawn based on the presented data.

\section{CARBON MONOXIDE PRODUCTION DURING FIRES; A SHORT REVIEW}

There is a large body of research focused on the production of carbon monoxide in fires (but only few publications are mentioned here for brevity), where it is generally agreed that there is a relation between carbon monoxide production and the equivalence ratio [3,9,11] or the mixture fraction [17]. 
The first attempt to correlate carbon monoxide (and other species) with the equivalence ratio was made by Beyler [3,5,6]. His ideas were further investigated at California Institute of Technology by Zukoski et al. with a slightly modified setup [4,7,9]. Later on, Gottuk and Roby proposed an engineering methodology, published for the first time in $2^{\text {nd }}$ edition of SFPE Handbook [18], which was then amended by Gottuk and Lattimer in subsequent editions [19,20]. That model attempts to take into account some additional CO formation and/or oxidation in the upper layer and the occurrence of external burning. The main correlation proposed by them is GER dependent. For that correlation with GER, they have proposed two equations. The choice of these equations depends on upper layer temperature limit $\langle 800 \mathrm{~K}$ or $>900 \mathrm{~K}$. The correlation for lower temperature limit is based mainly on Beyler's experiments in a hood with hexane, whereas the higher temperature case is based on Gottuk's study in a compartment with forced controlled inflow of air. That design allowed him to derive accurate information about mass of air entrained and thus the plume equivalence ratio [10,19]. The above methodology presents non-normalised yields of $\mathrm{CO}$ as they argued that these yields are independent of the fuel. According to these authors, their methodology may not give the maximum levels of yields but generally provided good results.

Most of the studies published before 1995 was reviewed by Pitts [11]. However, he extended the initial concept over following years resulting in publication of an algorithm for $\mathrm{CO}$ production in enclosure fires [21]. He did not propose any quantitative correlations but tried to explain governing mechanisms. The main ideas are described below. The first factor governing $\mathrm{CO}$ production was called by him the global equivalence ratio (GER) concept, based on hood experiments mentioned before. According to Pitts, $\mathrm{CO}$ yield can be correlated with GER. That correlation is fuel dependent but can be generalised between different groups of fuels. However, the GER concept cannot capture other phenomena which govern $\mathrm{CO}$ production. One has to consider additional three different mechanisms explained by Pitts, namely: direct entertainment of fresh air into the hot upper zone; pyrolizing of wood, if it exists, in the hot upper zone; and formation of additional $\mathrm{CO}$ in the upper zone with very high temperatures close to chemical equilibrium.

However, Pitts discovered later [22] that there was a numerical error in some calculations on which he based his assumptions regarding the GER concept in large scale tests. It did not invalidate his general algorithm however he concluded that GER cannot be globally calculated based on 'the fuel mass flow rate and the air flow rate through the doorway' [22]. According to him some part of the fresh air will not 'molecularly mix' with hot vitiated gases therefore the new approach to GER is required 'to include only the mass of air that is directly mixed into the upper-layer combustion gases by entrainment into the fire plume and/or the upper layer'[22]. In a more recent personal communication with Forell [23], he suggested 'discrete equivalence ratios for the plume, the upper layer and the compartment'.

A further important contribution was made by researchers at NIST. They examined generation of combustion products in compartment fires, both at reduced scale with moderate HRR <1 MW [24] and at full scale inside an ISO 9705 room with large HRRs [25]. These studies attempted to correlate mixture fraction [17] with generation of different combustion products including carbon monoxide and soot. Mixture fraction is directly related to the equivalence ratio [24] therefore comparison can be easily made with correlations based on GER.

A different approach is to establish correlations, usually fuel dependent, based on small scale bench tests, for example from the Purser tube [26]. This approach, which is being favoured by toxicology models was criticised for example by Babrauskas [12]. He argued that carbon monoxide yields are not fuel dependent in large scale compartment tests and hardly exceeds $0.2 \mathrm{~g} / \mathrm{g}$ for underventilated conditions. According to him, data from large and intermediate scale tests indicate that "there is only a very small effect of fuel chemistry on $\mathrm{CO}$ yield [12], thus conducting bench-scale tests on different products or materials to quantify a variable which hardly varies is not necessary" [12]. On the other hand, Stec et al. published recently [27] a comparison of the results from the tube furnace with larger scale tests and found a good agreement, at least for polypropylene and polyamide 66. Yet, no quantitative correlations have been proposed. Another comparison between small and large scale test of polypropylene and polyamide 66 was published by Andersson et al. [28]. However agreement between small and large scale data was found only for simple "pool" fire configuration in the large scale. No correlations were found when samples were installed (in the large scale) on the ceiling or on the walls.

An alternative methodology was used by Tewarson [29] by testing six common, synthetics polymers and one natural (wood) in the Fire Propagation Apparatus (FPA) [30]. Unique design of that apparatus allowed 
him to vary air supply thus to modify equivalence ratio [31]. He concluded that the generation of $\mathrm{CO}$ increases for higher equivalence ratios. Moreover, his correlations for $\mathrm{CO}$ were dependent on the chemical structure of fuels.

A new insight into the carbon monoxide generation in compartment fires came from a study performed by Wieczorek et al. [32-34]. He concluded that there is no uniformity of gaseous species concentration in the upper layer even for underventilated fires [33] as opposed to generally assumed well mixed conditions inside upper layer. He postulated that the GER concept is not adequate to fully describe the formation of carbon monoxide in compartment fires. He claimed also that there is a dependency of the $\mathrm{CO}$ yield on the opening width, not fully captured by the GER concept. Finally, he suggested that the effect of external burning due to flame extensions can be quantified using a 'non-dimensional parameter'. Based on experiments he was able to correlate yields of carbon monoxide with a non-dimensional parameter represented as the ratio of heat release Rrate (HRR) to the HRR when flame exits the enclosure. However it must be stressed that he calculated yields of carbon monoxide generated only inside the compartment without the effect of reactions outside. Therefore it can be considered as only "boundary conditions" at the exit of the compartment and therefore offers limited value for engineering calculations [23]. The other limitation of Wieczorek's methodology was pointed out by Forell [23]. He stressed that gas sampling during Wieczorek's research was done from inside the flame zone in some of the tests and the sampling probes were not water cooled. It had been shown earlier by Beyler [6] that sampling without water-cooling from inside the reaction zone gives higher $\mathrm{CO}$ levels, because uncooled probes may result in conversion of unburnt hydrocarbons into carbon monoxide. Beyler gave some examples from earlier work of Gross and Robertson during which both cooled and uncooled probes were used. "The uncooled probe measured $4.1 \%$ $\mathrm{CO}, 7.4 \% \mathrm{CO}_{2}$ and $12.8 \% \mathrm{O}_{2}$, while the cooled probe measured $1.2 \% \mathrm{CO}, 1.5 \% \mathrm{CO}_{2}$, and $20.4 \% \mathrm{O}_{2}$ (all measured on a dry basis)“" [6]. Taking that into account, one has to take with caution Wieczorek correlations.

\section{Generation of carbon monoxide in relation to smoke production}

Production of carbon monoxide depends on many factors, as discussed in the preceding section, yet there are still lots of gaps in the current knowledge. However, a question may arise if there is any cross correlation between carbon monoxide and smoke production, especially during underventilated compartment fires.

There are a few sources giving correlation in relation to overventilated conditions, which are listed in Table 1. However, no publication has been found that reports successful relationship between smoke and carbon monoxide for underventilated conditions. In fact the contrary has been shown by some researches. For instance, Leonard et al. [35] reported that for underventilated fires $\mathrm{CO}$ yield was insensitive to fuel structure (for ethylene and methane) whereas smoke yield was affected, thus there was no proportionality at all between $y_{s}$ and $y_{c o}$. Moreover, our earlier research [14] suggested that the single constant value is not applicable for underventilated combustion, at least for propane. Similarly, Ouf et al. [36] studied three different fuels for GER ranging from 0.009 to 0.547 . They reported CO/soot ratio increasing from 0.1 to 3 for the investigated range of GERs. On the other hand, different behaviours were reported by Tolocka et al. [37].They showed an increase in $\mathrm{CO}$ for higher temperatures as a result of oxidation of soot (thus a decrease in concentration of smoke) for richer equivalence ratios.

Finally, a short comment is required on data from large scale experiments performed recently at National Institute of Standard and Technology (USA). Ko et al. [24] claimed that their results were showing steady ratio between $y_{c o}$ and $y_{s}$ for their underventilated fires. They compared these data with the correlation of Köylü and Faeth [38]. Their data confirm that claim reasonably well for polystyrene and toluene but data points of heptane show large scatter. 
Table 1. Correlations between yield of smoke and yield of carbon monoxide for overventilated conditions.

\begin{tabular}{|l|l|}
\hline \multicolumn{1}{|c|}{ Publication } & \multicolumn{1}{|c|}{ Details of correlation between smoke and CO } \\
\hline$[39]$ & $\begin{array}{l}\text { "the ratio of optical density to CO concentration is } \\
\text { not absolutely constant from material to material, but } \\
\text { varies by about a factor of three in the most extreme } \\
\text { cases". }\end{array}$ \\
\hline$[38]$ & $y_{s}=(2.7 \pm 0.7) \times y_{c o}$ \\
\hline$[40]$ & $y_{s}=(2.3 \pm 0.4) \times y_{c o}$ \\
\hline$[41]$ & $y_{s}=(2.94 \pm 0.43) \times y_{c o}$ \\
\hline
\end{tabular}

\section{PRESENT EXPERIMENTS}

Experiments were performed in a corridor-like enclosure, $3 \mathrm{~m}$ long x $0.5 \mathrm{~m}$ x $0.5 \mathrm{~m}$ constructed from six cubic boxes (A to F) connected together, as illustrated in Fig. 1. The walls were made of refractory ceramic fibre board (Unifrax), having thickness of $0.04 \mathrm{~m}$ with an additional layer of MDF board (thickness 0.012 $\mathrm{m}$ ) as an external skin. The inflow of air was varied by using five different door-like openings in the front panel having dimensions (widths and heights, respectively): $7.5 \mathrm{~cm} \times 20 \mathrm{~cm}, 7.5 \mathrm{~cm}$ x $30 \mathrm{~cm}, 10 \mathrm{~cm}$ x 25 $\mathrm{cm}, 20 \mathrm{~cm} \times 20 \mathrm{~cm}$ and $25 \mathrm{~cm} \times 10 \mathrm{~cm}$. The fire was produced by a propane sandbox burner $(10 \mathrm{~cm} \times 20$ $\mathrm{cm}$ having the longer side parallel to the opening) flush with the floor of the corridor, located in the centre of the last box at the closed end (Box F). The fuel flow rate and hence the theoretical heat release rate was set by a mass flow controller. In addition HRR was measured by oxygen consumption calorimetry. Studied HRRs were in the range between 15 and $60 \mathrm{~kW}$ with further details of the experimental rig and performed experiments being reported elsewhere [13-16]. Figure 1 presents a layout of the experimental enclosure with the location of various sensors.

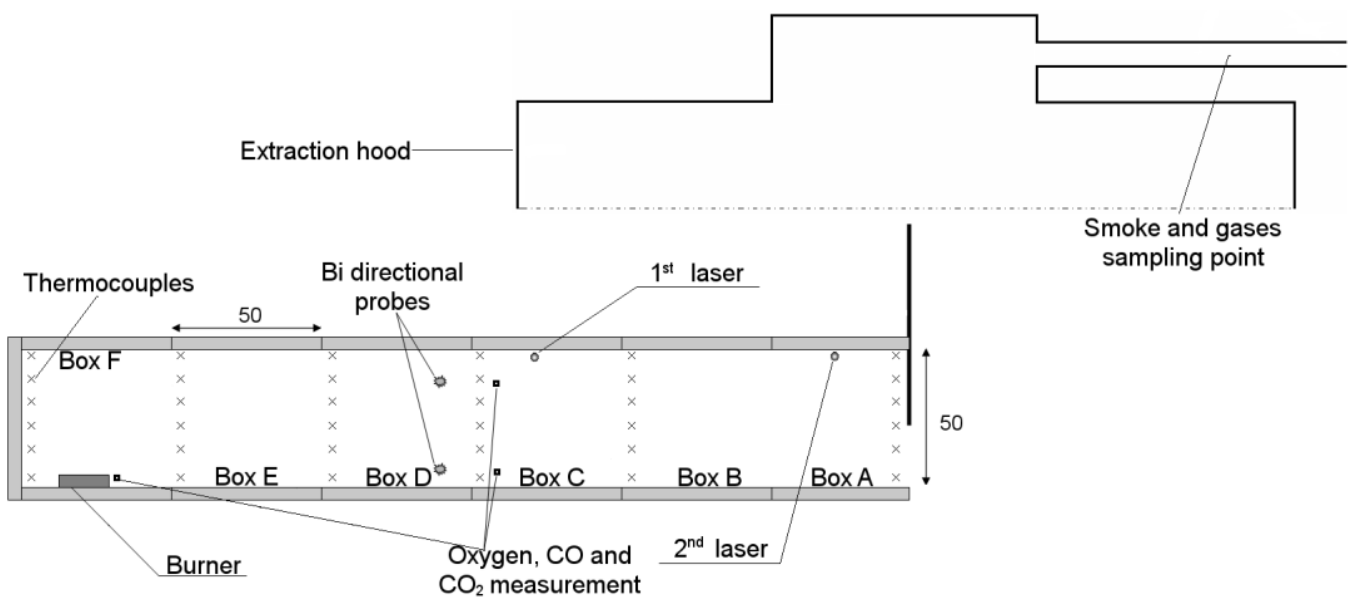

Fig. 1. Side view of the experimental compartment and instrumentation (all dimensions are in centimetres). Reprinted from [16] with permission.

Quantitative information on various gas concentrations by volume (on a dry basis) inside the enclosure were obtained simultaneously in three different locations for most of the tests. Three portable gas analysers supplied by Dark Star Research Ltd were used, two of them for oxygen, carbon dioxide and carbon monoxide including total hydrocarbons. Oxygen was measured by an electrochemical cell, whereas the other species by an infrared cell. A third gas analyser measured carbon monoxide and oxygen levels by electrochemical cells. 
Gas sampling followed the recommendations of Wieczorek et al. [33] for space average sampling by using stainless steel probes closed at one end and containing a set of holes of different sizes along the whole length of the tube. The sampling tubes had a length of $50 \mathrm{~mm}$ inside and external length of $50 \mathrm{~cm}$ (for cooling purposes), an external diameter of $12 \mathrm{~mm}$, with eleven holes of $4 \mathrm{~mm}$, eleven holes of $3 \mathrm{~mm}$ and eleven holes of $2.5 \mathrm{~mm}$. Different holes sizes assisted in uniform sampling from the whole inside length $(0.5 \mathrm{~m})$ of the tube. It was not possible to water-cool the sampling tubes with the small holes; but because the temperatures at the sampling points were less than $600{ }^{\circ} \mathrm{C}$ for most of the time (and much less near the bottom of the corridor) reactions leading to $\mathrm{CO}$ were possibly quenched. Moreover probes were cooled by convection (ambient temperature in the lab) just outside of enclosure so there was not much distance for possible $\mathrm{CO}-\mathrm{CO}_{2}$ conversion. If any conversion happens anyway, we could hypothesise that our design could induce overestimation of $\mathrm{CO}$ based on our literature review [6].

Repeatability of $\mathrm{CO}$ measurements is examined from two experiments at the same conditions. Plots from these experiments with different openings are shown in Fig. 2. The repeatability both inside and outside the corridor in the duct is excellent for both openings except for a time shift in the origin of recordings for the opening W7.5cm x $\mathrm{H} 30 \mathrm{~cm}$.

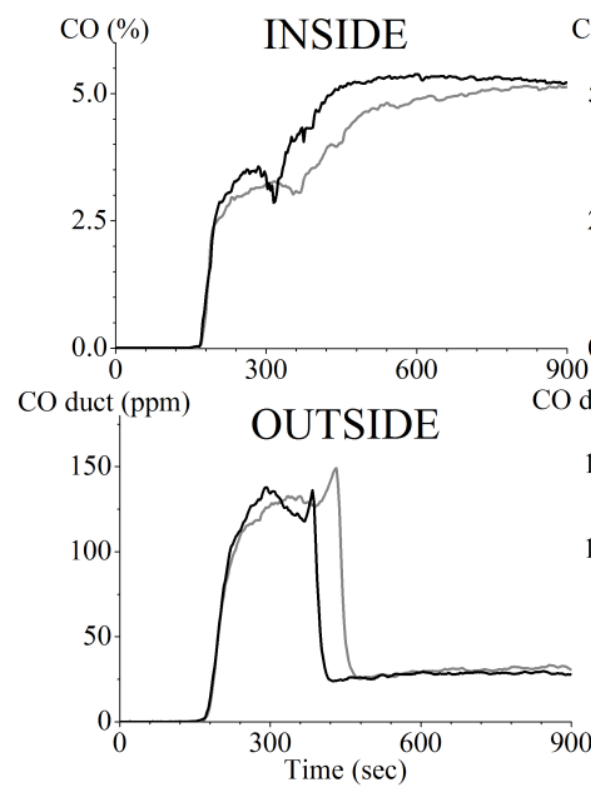

Opening $\mathrm{W} 7.5 \mathrm{~cm} \times \mathrm{H} 30 \mathrm{~cm}, \mathrm{HRR}=50 \mathrm{~kW}$
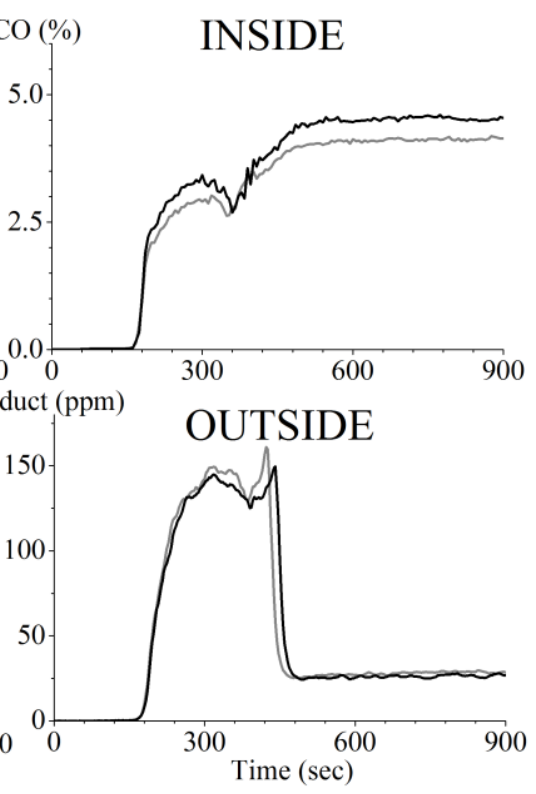

Opening $\mathrm{W} 10 \mathrm{~cm} \times \mathrm{H} 25 \mathrm{~cm}, \mathrm{HRR}=50 \mathrm{~kW}$

Fig. 2. Repeatability of carbon monoxide concentrations inside the corridor (top row) and outside in the exhaust duct (bottom row) for two different openings.

\section{RESULTS AND DISCUSSION}

\section{Behaviour of fires in the corridor enclosure}

This section summarises the flame behaviour in long corridors for underventilated conditions which is the focus of this work. Phenomenon described below was reported previously in more details by the authors [13-16]. A short description is however presented here to help the reader assessing the impact it may have on the carbon monoxide production in corridor-like enclosure.

Almost all the tests were designed to reach underventilated conditions by choosing a theoretical HRR (from known fuel supply rate) larger than the critical ventilation controlled HRR $\left(1500 \mathrm{AH}^{1 / 2}\right)$ to obtain a global equivalence ratio GER>1. The critical ventilation HRR was $26.85 \mathrm{~kW}$ for the largest opening employed in this study. Consequently, the majority of the tests was performed at HRR > $30 \mathrm{~kW}$, but not exceeding $60 \mathrm{~kW}$ because it was found that prolonged testing with HRRs larger than $60 \mathrm{~kW}$ was damaging the walls 
of the experimental rig. However the authors performed also a few tests with GER $<1$ which are not reported here but are fully described in [13].

It was revealed that the flames were detaching from the burner only for tests with GER $>1$. This statement is based not only on the visual observations through the opening but also temperature measurements inside supported with data from oxygen sensors [13]. 1. After detachment, the flames were travelling towards the opening where they stayed anchored in the vicinity of the opening having the excess fuel burning outside as shown in Fig. 3. The flow field behind the travelling flames was reverse to the flow field ahead of the flame. The flow and burning development in Fig. 3 was confirmed by measurements of temperature, concentration of various gases and velocity by bi-directional probes located inside the enclosure $[13,16]$. For the underventilated experiments with GER > 1, when the flames reached the opening there was no burning inside the corridor but the flames were at the interface between the corridor and the opening, as seen at the bottom of Fig. 3. Prior to this state the flames detached from the burner and then travelled along the corridor seeking fresh air, as seen at the two top diagrams of Fig.3. These flames may be called "travelling flames". The flame detachment and travel along the enclosure is different from "ghosting flames" reported earlier in the literature because ghosting flames are characterised by burning unsteadily in the volume above the fuel [43-46].

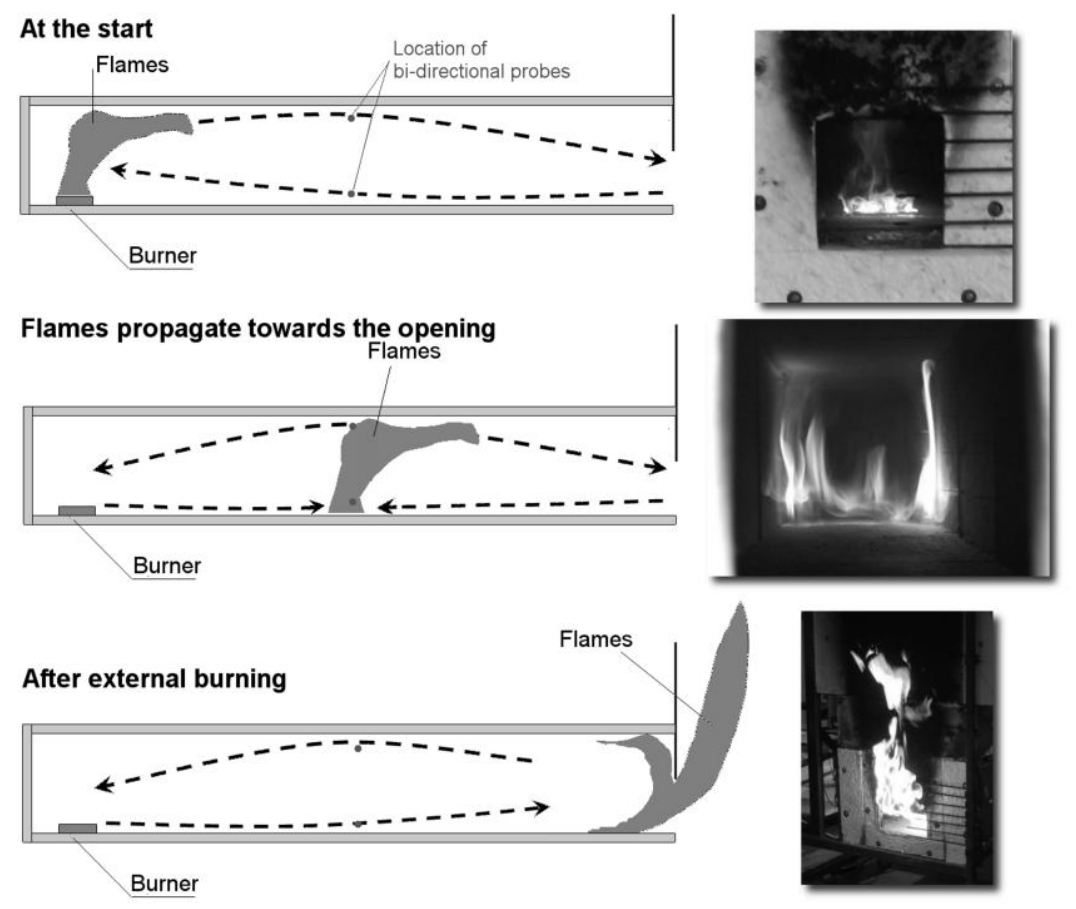

Fig. 3. Illustration of flames behaviour in the corridor. Supporting data available in $[13,16]$

\section{Carbon monoxide concentrations inside and outside the corridor in the exhaust duct}

\section{Observations}

Histories of heat release rates (HRR) and carbon monoxide concentrations inside and outside of the enclosure in the duct are presented in Fig. $4 \mathrm{a}$ for four different openings and a flow rate of propane corresponding to a theoretical heat release rate of $50 \mathrm{~kW}$ in all cases. The propane flow rate was set at the beginning of the experiment. The black solid curve in Fig. 4a represents the measured heat release rate history which basically consists of two steady state parts, one during the period the flames are inside the enclosure and the other during the period the flames are at the exit with the excess fuel burning outside (see Fig.3). During the former period shown by the shaded area in Fig. $4 \mathrm{a}$ the heat release rate is $1500 \mathrm{AH}^{1 / 2}$ and the burning is underventilated $\left(\mathrm{GER}=\mathrm{HRR}_{\text {theoretical }} / 1500 \mathrm{AH}^{1 / 2}\right)$; in contrast, during the latter period the excess fuel burns freely in air outside the enclosure and the heat release rate tends to reach approximately 
the theoretical heat release rate $(50 \mathrm{~kW})$. The decaying parts in Fig.4a occur after the flow of the fuel ceased.

The solid grey curve in Fig. 4 represents $\mathrm{CO}$ concentrations outside the corridor in the exhaust duct, whereas the dashed curve represents $\mathrm{CO}$ concentrations inside the enclosure at the upper layer of box $\mathrm{C}$ (see Fig.1). It is important to note that there is a difference in concentrations outside and inside the enclosure by two orders of magnitude for the underventilated conditions (shaded area in Fig.4) for which all $\mathrm{CO}$ produced in the enclosure enters the exhaust duct. The difference in concentrations is caused by dilution of combustion products with ambient air drawn in the exhaust duct as the following simple calculations illustrates. For example, measured concentrations of $\mathrm{CO}$ in the top diagram during underventilated conditions were 120 times higher inside the enclosure than in the exhaust duct where the exhaust flow rate was $1.55 \mathrm{~kg} / \mathrm{s}$. Because the outflow from the enclosure is the sum of the fuel supply rate and air inflow rate $\left(0.5 \mathrm{AH}^{1 / 2} \mathrm{~kg} / \mathrm{s}\right)$ into the enclosure one obtains a dilution ratio of about 153 , which is in good agreement with the difference in the concentrations being equal to 120 .

Figure 4aa reveals that the concentration of carbon monoxide outside the corridor decreases significantly as soon as external burning starts, whereas the concentration inside increases at that point. It is well known that the external burning plays a significant role in the reduction of $\mathrm{CO}$ concentrations outside the corridor $[10,11,14,19,20]$ because the excess fuel burns freely with air . On the other hand, the concentrations of CO inside the corridor increase behind the flame (see Fig.3) to much higher levels. We attribute the increase in carbon monoxide concentration inside the corridor to the reversal of the flow behind the travelling flame (Fig. 3) because hot gases move near the ceiling backwards towards the closed end of the corridor. This change of flow and recirculation of combustion products, shown by the dashed arrows in Fig. 3, was established from data of velocities and oxygen concentrations inside the enclosure as reported previously $[13,16]$.

An additional observation emerging from Fig. 4a is related to a small decrease in $\mathrm{CO}$ at the end of underventilated period. This decrease is observed both inside and outside and is related to the conversion of $\mathrm{CO}$ to $\mathrm{CO}_{2}$ (see Figs $4 \mathrm{~b}$ ) as the oxygen is suddenly reduced (see Fig. 4c) when the flames detach from the burner. We note that the small decrease in $\mathrm{CO}$ concentration clearly coincides with a small increase in $\mathrm{CO}_{2}$ levels as shown in Fig. 4b. Such oxidation was possible due to relatively high levels of oxygen being fed to the moving flame front as shown in Fig.4c. It is worth noting that as soon as oxygen level dropped significantly the conversion of $\mathrm{CO}$ to $\mathrm{CO}_{2}$ stopped.

\section{Correlations}

In order to investigate which factors influence the levels of $\mathrm{CO}$ concentrations inside the corridor we compared experiments with the same opening size but with different theoretical HRRs. Figure 5 presents carbon monoxide concentrations inside the corridor in the upper layer of box $\mathrm{C}$ (middle section Fig. 1). The left graph presents experiments with the opening having the dimensions: width $10 \mathrm{~cm}$, height $25 \mathrm{~cm}$; whereas the graph on the right presents experiments with the opening having the dimensions: width $7.5 \mathrm{~cm}$, height $30 \mathrm{~cm}$. Figure 6 presents $\mathrm{CO}$ concentrations measured in the same box but in the bottom layer. It is noted that the concentrations at the bottom layer are lower than that at the upper layer owing to dilution of the recirculating gases behind the flame with the fuel. Moreover it can be seen in Fig. 5 that for a fixed opening size the concentration correlates with the theoretical HRR, or in other words with the amount of supplied gaseous fuel. The only exception (experiments at 50 and $60 \mathrm{~kW}$ presented on the left) needs to be re-investigated as it is not clear if that was an instrumental error or some underlying phenomenon.

The $\mathrm{CO}$ concentrations behind the flames inside the corridor and the $\mathrm{CO}$ yield measured in the exhaust duct before the flames exit the corridor should correlate with the global equivalence ratio which controls the burning inside the enclosure in both cases. The global equivalence ratio GER is:

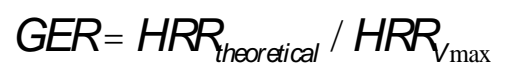

where $\mathrm{HRR}_{\text {theoretical }}$ is the theoretical heat release rate $(\mathrm{kW})$ calculated from the supply of propane gas by multiplying the amount of gas supplied $(\mathrm{g} / \mathrm{s})$ by the effective (lower) heat of combustion of propane, 
namely $43.7 \mathrm{~kJ} / \mathrm{g}$ [42], and $\mathrm{HRR}_{\mathrm{Vmax}}$ is the maximum ventilation controlled heat release rate expressed in $\mathrm{kW}$ and calculated as follows $[13,16]$ :

$H R R_{V \max }=1500 A H^{1 / 2} \mathrm{~kW}$

where $A\left(\mathrm{~m}^{2}\right)$ and $H(\mathrm{~m})$ are the area and height of the opening, respectively.
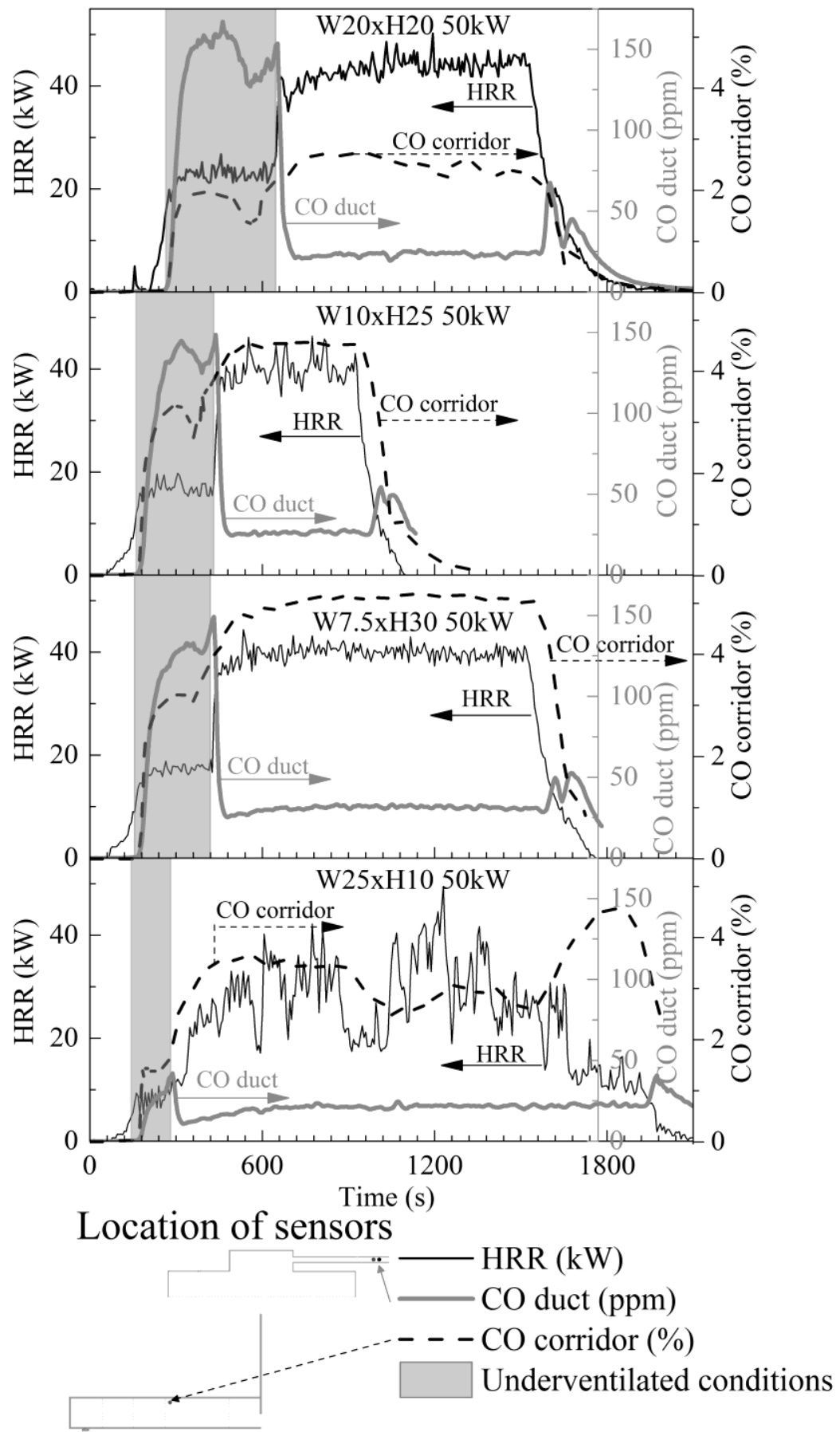

Fig. 4a. Carbon monoxide inside the corridor in the upper layer of box $\mathrm{C}$ and in the exhaust duct together with the measured heat release rate. 


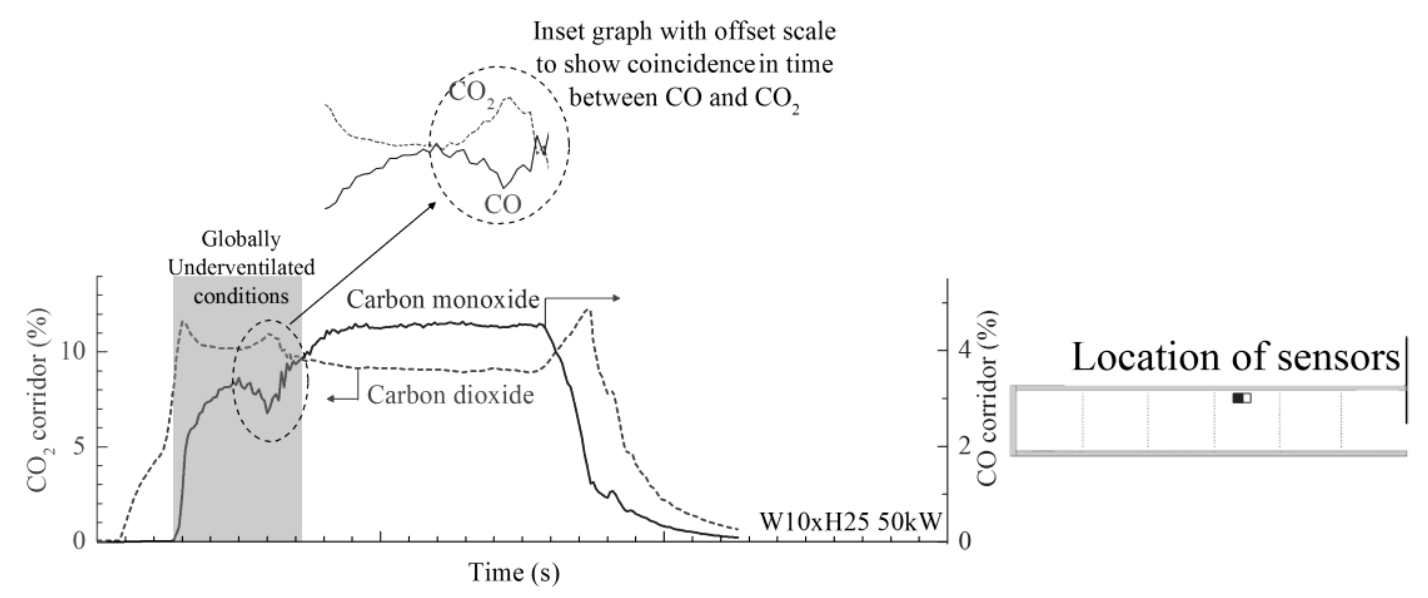

Fig. 4b. Carbon monoxide and carbon dioxide measured inside the corridor in the upper layer of box C.

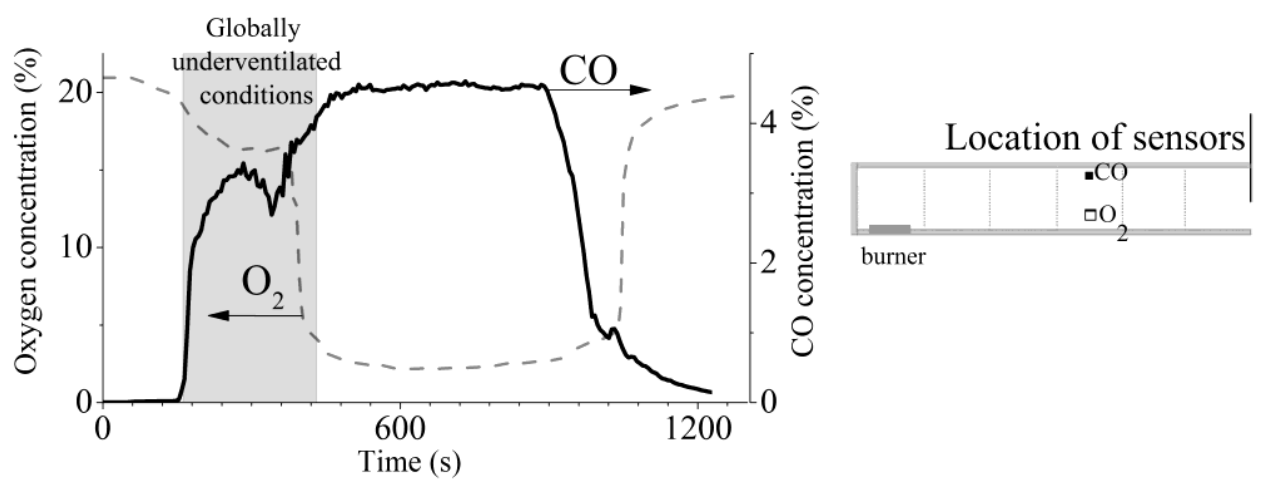

Fig.4c. Carbon monoxide inside the corridor in the upper layer of box $\mathrm{C}$ together with oxygen concentration in the bottom layer

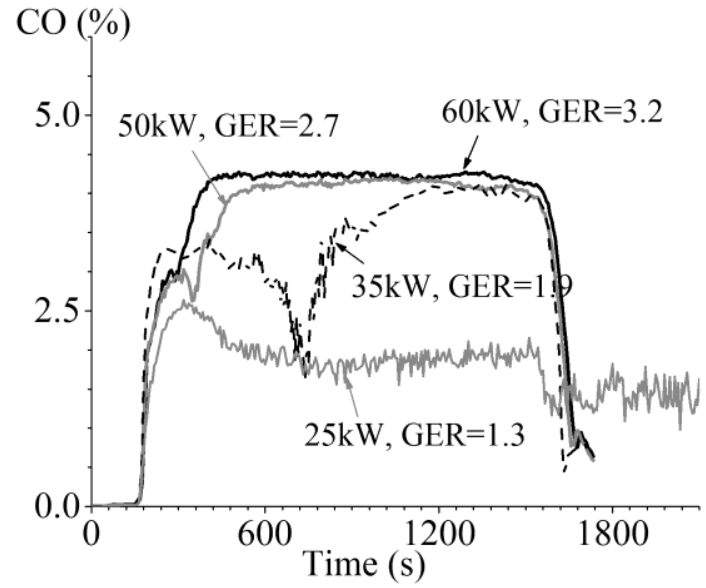

Carbon monoxide concentration, upper layer of box Opening $\mathrm{W} 10 \mathrm{~cm} \times \mathrm{H} 25 \mathrm{~cm}$,

Critical HRR $=1500 \mathrm{AH}^{1 / 2}=18.75 \mathrm{~kW}$

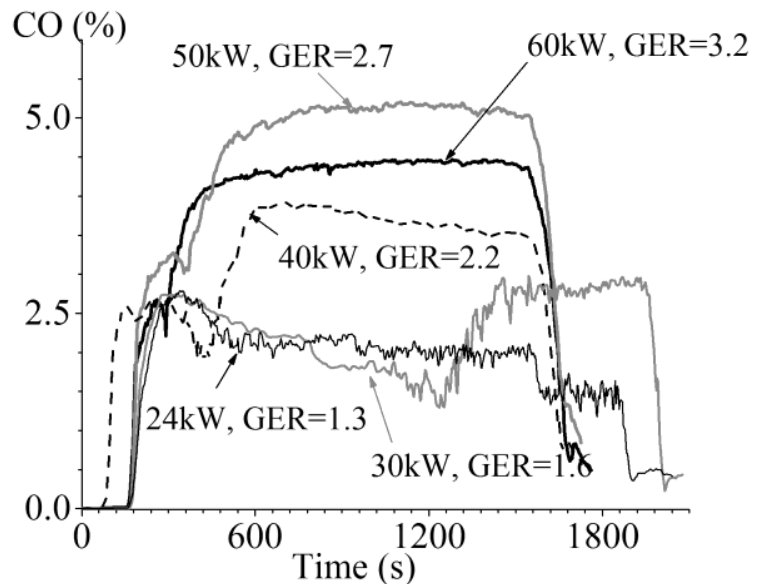




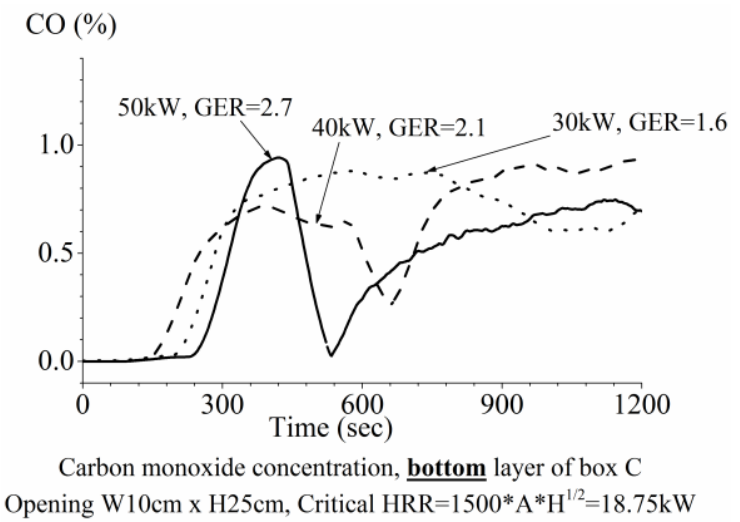

Fig. 6. Carbon monoxide concentrations inside the corridor (bottom layer, middle section) for one opening and various HRRs.

The CO concentrations inside the corridor and the CO yield in the duct are plotted versus GER in Figs. 7 and 8 respectively. The correlation in Fig. 7 for $\mathrm{CO}$ concentrations inside the enclosure behind the flames is new whereas the CO yield in the duct is compared in Fig. 8 with other similar correlations $[17-19,29,39]$. In both cases in the present study, the $\mathrm{CO}$ values increase first with the GER reaching a maximum at about 2-3 and then decrease for high GERs because fuel is too rich to be oxidized. The trends of the present data in Fig. 8 agree with results in [29,39] but are different from the results in [17-19] which show a constant value at high GERs. In addition, much higher values are reported by Leonard et al. [35] for laminar flames.

The present results as well as some of the previous results [1-24] can be explained by noting that in general there is a state relationship between CO concentration and mixture fraction (directly related to GER) for laminar flames depending on fuel [43]. Depending on the level of fluctuations the CO concentrations in turbulent flows are lower than in a laminar flame and can be different for different flow conditions. Consequently, the $\mathrm{CO}$ concentrations depend on the fuel as well as on the type of flows expected in fires. We also note that additional reactions affecting $\mathrm{CO}$ may occur if the combustion products pass through areas where high temperatures (over $800^{\circ} \mathrm{C}$ ) prevail [21,22]. It should be also mentioned that local value of equivalence ratio may be more meaningful compared to the global value however such measurements were not available in this work.

Finally we show in Fig. 9 the ratio of CO yield to smoke yield $\left(y_{c d} / y_{s}\right)$ versus GER before the flames exit the corridor. In contrast to over ventilated fires where the ratio is constant, the ratio of $y_{c o} / y_{s}$ rapidly increases with GER greater than one reaching the value of 110 for GER=3. This ratio will depend on the type of the fuel and its tendency to produce smoke. Our proposed explanation is based on possible differences in $\mathrm{CO}$ production as compared to soot production. We have demonstrated previously [13] that soot production is related to residence time inside the corridor rig whereas we have not observed such dependency for CO production. Consequently that ratio $\left(y_{c o} / y_{s}\right)$ cannot be a constant as shown also in [14].

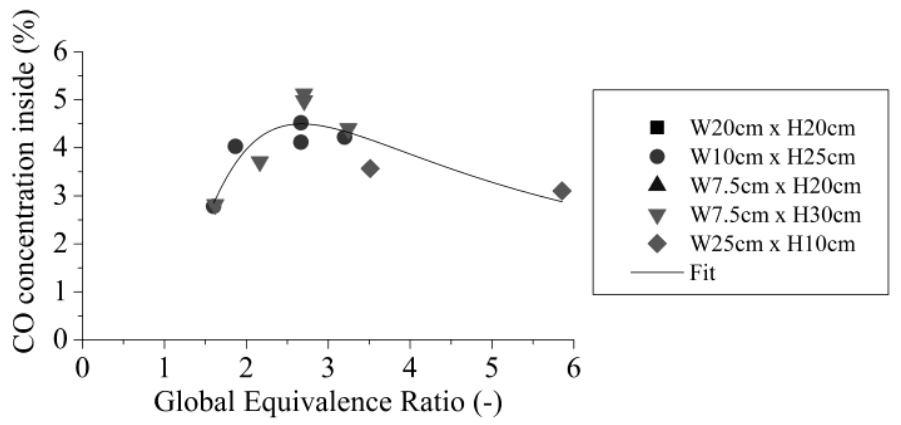

Fig. 7. . Time averaged concentrations of Carbon monoxide inside the corridor (upper layer, box C) during the quasi steady state period (after flames emerged outside) as a function of global equivalence ratio. Explanation of correction for GER in the last opening is given in [13]. Fit for the authors' data is as follows: $\mathrm{y}=0.4281 \times \mathrm{GER}^{\left(6.496 \times \mathrm{GER}^{\wedge}(-1.01624)\right.}$ 


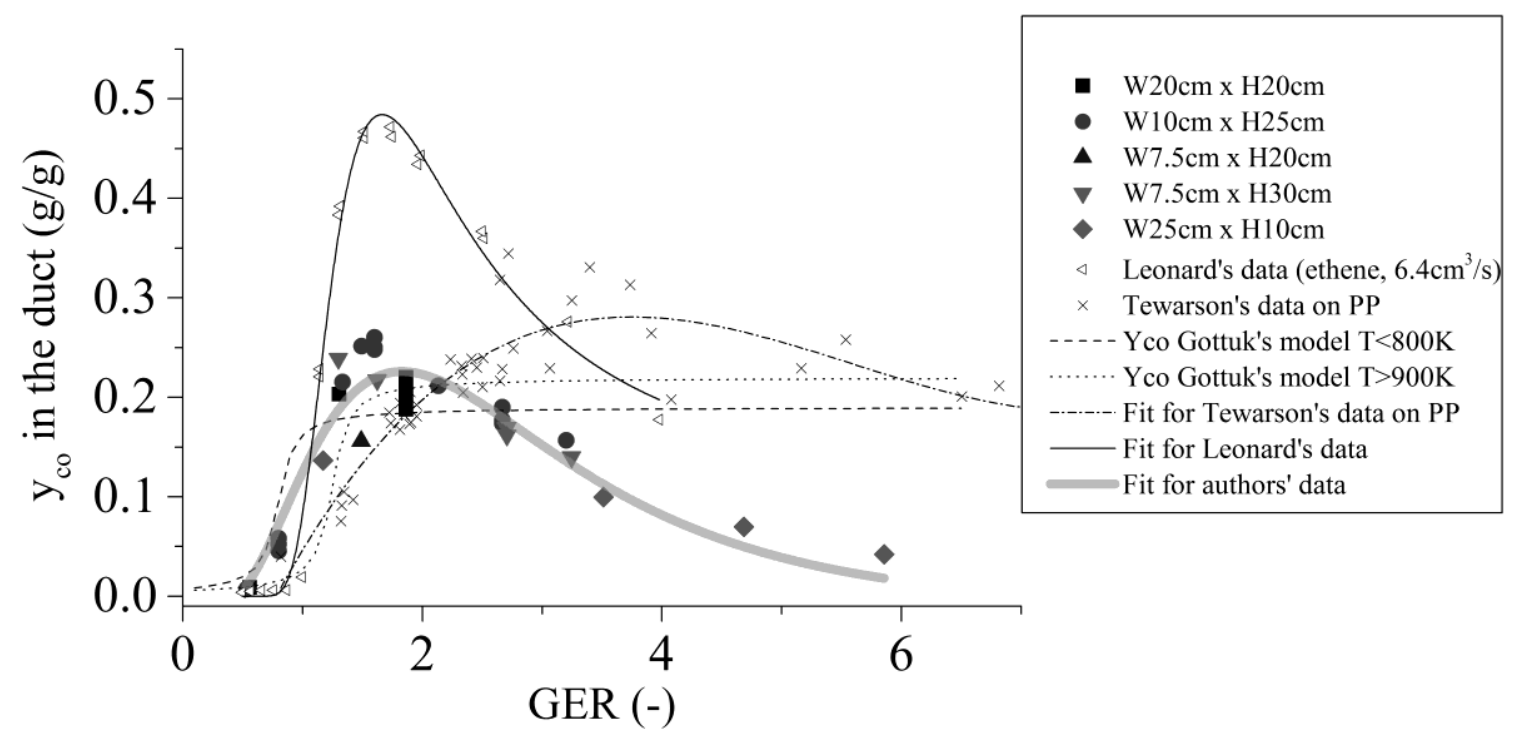

Fig. 8. Present experimental data on yields of carbon monoxide downstream of the compartment together with Gottuk's et al. correlations [18-20], Tewarson data for one polymer [29], and Leonard's et al. data for ethane [35]. Our data shows measurements in the duct before external burning. Equation for the fit of Tewarson's data is as follows: $y=-0.20839+0.31401 \times \mathrm{GER}-0.06305 \times \mathrm{GER}^{2}+0.00376 \times \mathrm{GER}^{3}$, Equation for the fit of Leonard's data is as follows: $\left.y=0.08353 \times \mathrm{GER}^{\left(9.37428 \times \mathrm{GER}^{\wedge}(-1.96248)\right.}\right)$. Equation for the fit of the authors' data is as follows: $y=-0.01286+0.74147 /(\operatorname{sqrt}(2 \times \mathrm{PI}) \times 0.57458 \times \mathrm{GER})$ $\times \exp \left(-(\ln (\mathrm{GER} / 2.54587))^{2 /\left(2^{*} 0.57458^{\wedge} 2\right)}\right)$. Explanation of correction for GER in the last opening is given in [13]

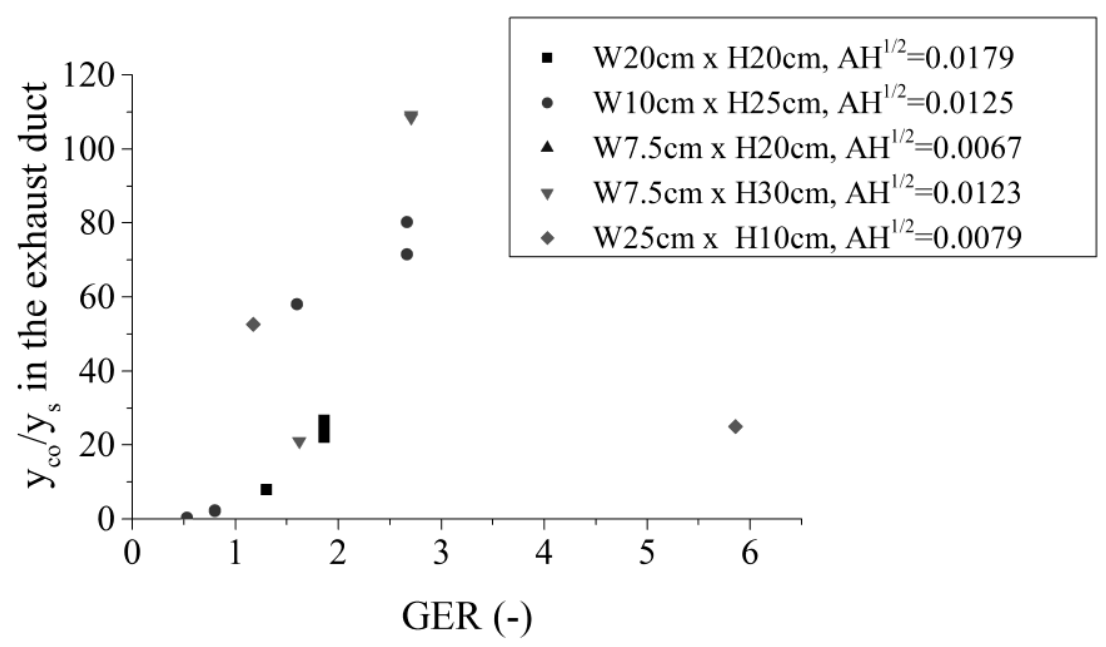

Fig.9. The ratio of carbon monoxide yield to smoke yield as a function of global equivalence ratio before flames exit the corridor..

\section{CONCLUSIONS}

The main conclusions are as follows:

- Recirculation of gases behind travelling flames (Fig. 3) is responsible for a substantial increase of the concentration of carbon monoxide inside the corridor after external burning starts (Fig. 4a).

- A conversion of $\mathrm{CO}$ to $\mathrm{CO}_{2}$ with a concurrent reduction of oxygen occurs inside the enclosure at the end of underventilated conditions as the travelling flame front reaches the open end (Figs. $4 \mathrm{~b}$ and $4 \mathrm{c}$ ). 
- The concentration of CO inside the corridor, behind the flame front, is controlled by the global equivalence ratio (GER), namely it first increase with GER at lower GERs and then decreases at higher GERs (Fig. 7).

- A decrease is also observed for CO yields at higher GERs for measurements outside the corridor for underventilated conditions before external burning occurs in contrast with some literature data (Fig. 8).

- Finally the present results show that the relationship reported in the literature, between smoke and carbon monoxide production during overventilated conditions, $\mathrm{y}_{\mathrm{co}} / \mathrm{y}_{\mathrm{s}} \approx$ constant, is no longer valid during an underventilated enclosure fire. The present results show that the ratio $\mathrm{y}_{\mathrm{co}} / \mathrm{y}_{\mathrm{s}}$, is not constant but increases for global equivalence ratios of the enclosure greater than one (Fig. 11).

- The present results as well as some of the previous results [1-24] can be explained by noting that in general there is a state relationship between $\mathrm{CO}$ concentration and mixture fraction (directly related to GER) for laminar flames depending on fuel [43]. If the flames are turbulent, the CO concentration can be calculated from the probability distribution of mixture fraction and the laminar state relations [43]. Depending on the level of fluctuations the CO concentrations in turbulent flows are lower than in laminar flames and can be different for different flow conditions. Consequently, the $\mathrm{CO}$ concentrations depend on the fuel and the type of flows expected in fires. We also note that additional reactions affecting $\mathrm{CO}$ may occur if the combustion products pass through areas where high temperatures (over $800{ }^{\circ} \mathrm{C}$ ) prevail $[21,22]$. It is possible to use the methodology in [43] to generalize and extend the present data for other fuels.

In addition, $\mathrm{CO}$ production is different from soot production, the latter depending on residence time in contrast to the former. So their ratio cannot be a constant.

\section{ACKNOWLEDGEMENT}

The authors would like to acknowledge the financial support of the AIRCRAFT project. Technical assistance of Mr M. McKee, Mr B. Veighy and Mr K. Kowalski is also greatly appreciated. Finally, all the comments from the reviewers are highly valued.

\section{REFERENCES}

[1] Rasbash, D.J. and Stark, G.W.V., The Generation of Carbon Monoxide by Fires in Compartments. Fire Research Note No 614, Fire Research Station. BRE Trust, UK, 1966.

[2] Pitts, W.M. "Carbon Monoxide Production and Prediction. NISTIR 4449," U.S./Japan Government Cooperative Program on Natural Resources (UJNR). Fire Research and Safety., 1990, pp. 33-39.

[3] Beyler, C., Development and burning of a layer of products of incomplete combustion generated by a buoyant diffusion flame, $\mathrm{PhD}$ thesis, 1983.

[4] Zukoski, E.E., Kubota, T. and Lim, C.S., Experimental Study of Environment and Heat Transfer in a Room Fire. Mixing in Doorway Flows and Entrainment in Fire Plumes, National Bureau of Standards, USA, 1985.

[5] Beyler, C.L., (1986), Major species production by diffusion flames in a two-layer compartment fire environment, Fire Safety Journal 10: 47-56, http://dx.doi.org/10.1016/0379-7112(86)90031-7.

[6] Beyler, C. "Major Species Production By Solid Fuels In A Two Layer Compartment Fire Environment," Fire Safety Science -- Proceedings of the First International Symposium, 1986, pp. 431-440, http://dx.doi.org/10.3801/IAFSS.FSS.1-431

[7] Zukoski, E., Toner, S., Morehart, J. and Kubota, T., "Combustion Processes In Two-layered Configuations," Fire Safety Science -- Proceedings of the Second International Symposium, 1989, pp. 295-304, http://dx.doi.org/10.3801/IAFSS.FSS.2-295. 
[8] U.S./Japan Government Cooperative Program on Natural Resources (UJNR). Fire Research and Safety., NIST, USA, 1990.

[9] Morehart, J., Zukoski, E. and Kubota, T. "Characteristics Of Large Diffusion Flames Burning In A Vitiated Atmosphere," Fire Safety Science -- Proceedings of the Third International Symposium, 1991, pp. 575-583, http://dx.doi.org/10.3801/IAFSS.FSS.3-575

[10]Gottuk, D., Generation of Carbon Monoxide in Compartment Fires, PhD thesis, 1992.

[11]Pitts, W., (1995), The global equivalence ratio concept and the formation mechanisms of carbon monoxide in enclosure fires, Progress in Energy and Combustion Science 21: 197-237, http://dx.doi.org/10.1016/0360-1285(95)00004-2.

[12]Babrauskas, V., (1995), The generation of CO in bench-scale fire tests and the prediction for real-scale fires, Fire Mater. 19: 205-213, http://dx.doi.org/10.1002/fam.810190503.

[13]Ukleja, S., Smoke and carbon monoxide production in underventilated enclosure fires, $\mathrm{PhD}$ thesis, 2012.

[14]Ukleja, S., Delichatsios, M. and Lee, Y. "Carbon monoxide and smoke production downstream of a compartment for underventilated fires," Fire Safety Science -- Proceedings of the Ninth International Symposium, 2008, pp. 849-860, http://dx.doi.org/10.3801/IAFSS.FSS.9-849

[15]Ukleja, S., Delichatsios, M. and Zhang, J. "Smoke Concentrations Inside and Outside of Corridor-Like Enclosure Fires," 7th Mediterranean Combustion Symposium, Chia Laguna, Cagliari, Sardinia, Italy, 2011.

[16]Ukleja, S., Delichatsios, M., Delichatsios, M. and Zhang, J., (2013), Smoke concentrations inside and outside of a corridor-like enclosure, Fire Safety Journal 60: 37-45, http://dx.doi.org/10.1016/j.firesaf.2013.03.009.

[17]Bilger, R., (1977), Reaction rates in diffusion flames, Combustion and Flame 30: 277-284, http://dx.doi.org/10.1016/0010-2180(77)90076-1.

[18]Gottuk, D. and Roby, R. "Effect of Combustion Conditions on Species Production," SFPE handbook of fire protection engineering (2nd ed), DiNenno, P., Beyler, C. (eds), National Fire Protection Association; Society of Fire Protection Engineers, Quincy, Mass, Boston, Mass, 1995, pp. 2-64 - 2-84.

[19]Gottuk, D. and Lattimer, B. "Effect of Combustion Conditions on Species Production," SFPE handbook of fire protection engineering ( $3 r d$ ed), DiNenno,P.,J., Drysdale, D., Beyler, C.L. (eds), National Fire Protection Association, Quincy, Mass, Boston, Mass, 2002, pp. 2-54 - 2-82.

[20]Gottuk, D. and Lattimer, B. "Effect of Combustion Conditions on Species Production," SFPE handbook of fire protection engineering (4th ed), DiNenno,P.,J., Drysdale, D., Beyler, C.L. (eds), National Fire Protection Association, Quincy, Mass, Boston, Mass, 2008, pp. 2-67 - 2-95.

[21]Pitts, W. “An Algorithm For Estimating Carbon Monoxide Formation In Enclosure Fires," Fire Safety Science -- Proceedings of the Fifth International Symposium, 1997, pp. 535-546, http://dx.doi.org/10.3801/IAFSS.FSS.5-535

[22]Pitts, W. “Toxic yield," Technical Basis for Performance Based Fire Regulations. A Discussion of Capabilities, Needs and Benefits of Fire Safety Engineering. United Engineering Foundation Conference Proceedings., 2001, pp. 76-88.

[23]Forell, B., A Methodology to assess Species Yields of Compartment Fires by means of an extended Global Equivalence Ratio Concept, $\mathrm{PhD}$ thesis, 2007.

[24]Ko, G., Hamins, A.,Bundy, M., Johnsson, E., Kim, S. and Lenhert, D., (2009), Mixture fraction analysis of combustion products in the upper layer of reduced-scale compartment fires, Combustion and Flame 156: 467-476, http://dx.doi.org/10.1016/j.combustflame.2008.08.012.

[25]Lock, A., Bundy, M., Johnsson, E., Hamins, A., Hyun Ko, G. and Hwang, C Experimental Study of the Effects of Fuel Type, Fuel Distribution, and Vent Size on Full-Scale Underventilated Compartment 
Fires in an ISO 9705 Room. NIST Technical Note 1603, National Institute of Standards and Technology, 2008.

[26]British Standards Institution, Tube furnace method for the determination of toxic product yields in fire effluent. BS 7990:2003(BS 7990:2003), British Standards Institution, 2003.

[27]Stec, A., Hull, T., Purser, J. and Purser, D., (2009), Comparison of toxic product yields from benchscale to ISO room, Fire Safety Journal 44: 62-70, http://dx.doi.org/10.1016/j.firesaf.2008.03.005.

[28]Andersson, B., Markert, F. and Holmstedt, G., (2005), Combustion products generated by heteroorganic fuels on four different fire test scales, Fire Safety Journal 40: 439-465, http://dx.doi.org/10.1016/j.firesaf.2005.03.002.

[29]Tewarson, A., JIANG, F. and MORIKAWA, T., (1993), Ventilation-controlled combustion of polymers, Combustion and Flame 95: 151-169, http://dx.doi.org/10.1016/0010-2180(93)90058-B.

[30]ASTM, Standard Test Methods for Measurement of Synthetic Polymer Material Flammability Using a Fire Propagation Apparatus (FPA). E 2058-03(E 2058-03), ASTM, 2003.

[31]Tewarson, A. and Steciak, J., (1983), Fire ventilation, Combustion and Flame 53: 123-134, http://dx.doi.org/10.1016/0010-2180(83)90011-1.

[32]Wieczorek, C., Carbon Monoxide Generation and Transport From Compartment Fires, PhD thesis, 2003.

[33]Wieczorek, C.J., (2004), An Evaluation of the Global Equivalence Ratio Concept for Compartment Fires: Data Analysis Methods, Journal of Fire Protection Engineering 14: 9-31, http://dx.doi.org/10.1177/1042391504034743.

[34]Wieczorek, C.J., (2004), Evaluating the Global Equivalence Ratio Concept for Compartment Fires: Part II-Limitations for Correlating Species Yields, Journal of Fire Protection Engineering 14: 175-197, http://dx.doi.org/10.1177/1042391504041471.

[35]Léonard, S., Mulholland, G., Puri, R. and Santoro, R., (1994), Generation of CO and smoke during underventilated combustion, Combustion and Flame 98: 20-IN4, http://dx.doi.org/10.1016/00102180(94)90195-3.

[36]Ouf, F.-X., Vendel, J., Coppalle, A., Weill, M. and Yon, J., (2008), Characterization of Soot Particles in the Plumes of Over-Ventilated Diffusion Flames, Combustion Science and Technology 180: 674698, http://dx.doi.org/10.1080/00102200701839154.

[37]Tolocka, M.P., Richardson, P.B. and Houston Miller, J., (1999), The effect of global equivalence ratio and postflame temperature on the composition of emissions from laminar ethylene/air diffusion flames, Combustion and Flame 118: 521-536, http://dx.doi.org/10.1016/S0010-2180(99)00025-5.

[38]Köylü, Ü.Ö. and Faeth, G.M., (1991), Carbon monoxide and soot emissions from liquid-fueled buoyant turbulent diffusion flames, Combustion and Flame 87: 61-76, http://dx.doi.org/10.1016/00102180(91)90027-9.

[39]Friedman, R. "Some Unresolved Fire Chemistry Problems," Fire Safety Science -- Proceedings of the First International Symposium, 1986, pp. 349-359, http://dx.doi.org/10.3801/IAFSS.FSS.1-349

[40]Mulholland, G., Janssens, M., Yusa, S., Twilley, W. and Babrauskas, V. “The Effect Of Oxygen Concentration On Co And Smoke Produced By Flames," Fire Safety Science -- Proceedings of the Third International Symposium, 1991, pp. 585-594,

[41]Tewarson, A. "Carbon monoxide and smoke emissions in fires," Interflam 2007: Proceedings of the eleventh international conference, 2007, pp. 1059-1069.

[42]Tewarson, A. "Generation of Heat and Chemical Compounds in Fires," SFPE handbook of fire protection engineering (4th ed), DiNenno,P.,J., Drysdale, D., Beyler, C.L. (eds), National Fire Protection Association, Quincy, Mass, Boston, Mass, 2008. 
[43]Delichatsios, M. and Mathews, M. “A New Simplified Pdf Method For Calculating Major Species Concentrations And Burning In Turbulent Fires," Fire Safety Science -- Proceedings of the Second International Symposium, 1989, pp. 149-158., , http://dx.doi.org/10.3801/IAFSS.FSS.2-149

[44]Most, J.-M., Saulnier, J., (2011) Under-Ventilated Wall Fire Behaviour during the Post- Flashover Period, Journal of Applied Fluid Mechanics 4: 129-135.

[45]Bertin, G., Most, J.-M., Coutin, M., (2002) Wall fire behavior in an under-ventilated room, Fire Safety Journal 37: 615-630, http://dx.doi.org/ 10.1016/S0379-7112(02)00016-4

[46]Audouin, L., Such, J., Malet, J., Casselman, C., “A Real Scenario For A Ghosting Flame,” Fire Safety Science -- Proceedings of the Fifth International Symposium, International Association for Fire Safety Science, 1997, pp. 1261-1272, http://dx.doi.org/10.3801/IAFSS.FSS.5-1261 